\title{
Curso de Construção de Páginas Web para Professores de Matemática: da Realização ao Acompanhamento em Momentos Distintos
}

\author{
Claudia Brandelero Rizzi ${ }^{1}$, Guilherme Galante ${ }^{1}$, \\ Pétterson Vinícius Pramiu ${ }^{1}$, Rogério Luis Rizzi ${ }^{1}$ \\ ${ }^{1}$ Centro de Ciências Exatas e Tecnológicas \\ Universidade Estadual do Oeste do Paraná (UNIOESTE) \\ Caixa Postal 711 - 85.819-110 - Cascavel-PR \\ \{claudia.rizzi,guilherme.galante, rogerio.rizzi\}@unioeste.br \\ ppramiulgmail.com
}

\begin{abstract}
This article presents a discussion arising from the proposal of a web pages construction course that had audience of 25 mathematics teachers of the Educational Development Program offered by Paraná state. Subsequently, we track which teachers have continued to maintain the pages and used them as support for their educational activities. In the first round, 16 months after the end of the course, only one teacher was still updating their pages. In the second round, 52 months after the end of the course, this same teacher continued to maintain the pages. Final discussions are made considering the offer of training courses for teachers.
\end{abstract}

Resumo. Este artigo apresenta discussões decorrentes da proposição de um curso de produção de páginas web que teve como público alvo 25 professores de matemática participantes do Programa de Desenvolvimento Educacional do Paraná (PDE). Verificou-se se esses professores deram continuidade à manutenção dessas páginas e se as utilizaram como apoio às suas atividades pedagógicas. No primeiro acompanhamento, decorridos 16 meses da realização do curso, apenas um professor continuava atualizando suas páginas. No segundo acompanhamento, decorridos 52 meses da realização do curso, esse mesmo professor continuava a mantê-la. Discussões decorrentes são feitas considerando tanto a oferta de cursos de formação para professores quanto o uso das Tecnologias de Informação e Comunicação (TICs) em sala de aula.

\section{Introdução}

No Brasil, a importância atribuída ao uso dos computadores e das Tecnologias de Informação e Comunicação (TICs) no ambiente educacional decorreu historicamente da expectativa de que esse poderia ser um caminho para modificar o paradigma então vigente, em geral, instrucionista. Posteriormente, essa importância teve como sustentação, seu impacto em relação às novas exigências sociais, culturais e laborais. Inseridos em uma ou outra dessas motivações, governos, escolas e professores buscaram (e continuam buscando) capacitação pessoal, recursos de hardware e software, além de suporte e apoio a essas ações. Passados mais de 40 anos de Informática na Educação no Brasil, particularmente em termos de capacitação pessoal, cursos ainda são oferecidos visando contribuir 
para que professores estejam aptos ao trabalho pedagógico realizado com a utilização dos computadores e das TICs.

Este trabalho apresenta discussões sobre uma atividade envolvendo a formação de professores para a elaboração e utilização de páginas web como ferramenta educacional para o ensino e a aprendizagem de Matemática e o acompanhamento posterior à conclusão do curso. O público alvo do curso eram professores de Matemática vinculados ao Programa de Desenvolvimento Educacional (PDE) do Paraná. O objetivo deste Programa é aprimorar a qualidade da educação básica no Estado através de atividades teóricas e práticas orientadas por professores vinculados a Instituições de Ensino Superiores públicas paranaenses visando a produção de conhecimento e mudanças qualitativas na prática escolar.

\section{O curso de criação de websites e seu acompanhamento}

O curso prático foi realizado no dia 05/02/2010, em um dos laboratórios de Informática da Universidade Estadual do Oeste do Paraná (UNIOESTE) em Cascavel-PR, utilizando a ferramenta Google Sites, um serviço disponibilizado pela Google cujo objetivo é facilitar a criação de websites [Google Sites 2014]. Teve duração de 8 horas e contou com a participação de 25 professores de Matemática participantes do PDE. O curso foi organizado da seguinte forma. Inicialmente foram apresentadas as potencialidades do Google Sites através de um site exemplo, desenvolvido pela equipe docente, objetivando exemplificar ao professor participante, as diversas possibilidades de utilização do mesmo no apoio pedagógico. Em seguida, os professores deram início ao processo de criação de seus sites individuais. Toda a explicação sobre como configurar as páginas, criar novas, adicionar link, fotos, vídeos, entre outros, foi feita de forma sincronizada, ou seja, os professores exercitavam cada uma das possibilidades que eram apresentadas no multimídia em suas próprias páginas e analisavam os efeitos. Quando havia dúvidas, a equipe docente efetuava o atendimento individual. Cada professor teve sua página web construída e personalizada. Também tiveram noções sobre como criar vídeos simples, postá-los no Youtube [Youtube 2014] vinculando-os as suas páginas.

Nos primeiros três meses posteriores à realização do curso, contatos foram feitos por e-mail e visitas foram efetuadas às páginas que os professores elaboraram para acompanhar a evolução das mesmas. Sugestões e orientações técnicas foram dadas para aqueles que procuraram auxílio. Passados 16 meses do término do curso, enviou-se um questionário aos participantes na tentativa de identificar se e como as informações adquiridas à época estavam sendo empregadas no dia-a-dia destes profissionais.

Seis dos 25 professores responderam ao questionário. Dois professores efetuaram manutenções nas páginas criadas, decorridos 16 meses da conclusão do mesmo. 96\% dos professores que participaram do curso não puderam ou quiseram dar continuidade às atividades práticas decorrentes dos conhecimentos adquiridos. Os principais motivos apresentados pelos professores que responderam ao questionário foram a falta de tempo para se dedicar à manutenção das páginas, as dificuldades técnicas encontradas para sua manutenção e a desmotivação decorrente do fato de que nem todos os alunos têm acesso à internet, e portanto, nem todos podem usufruir dos materiais ali disponibilizados.

Constatou-se que um professor participante do curso estava utilizando as páginas construídas para fins educacionais. No site que construiu com o Google Sites, postou cu- 
riosidades sobre a Matemática, disponibilizou alguns materiais aos alunos como tutoriais e outros textos. Organizou-a nas subpáginas Home, Contato, Curiosidades, Downloads, Ensino Fundamental e Ensino Médio. As duas últimas subpáginas foram subdivididas em outras subpáginas, sendo que cada uma delas estava relacionada a uma turma: $6^{\circ}$ ano, $7^{\circ}$ ano, $8^{\circ}$ ano, $9^{\circ}$ ano do ensino fundamental, e $1^{\circ}$ ano, $2^{\circ}$ ano e $3^{\circ}$ ano do ensino médio. Em cada uma delas, disponibilizou pelo menos uma atividade a ser desenvolvida pelos alunos daquela turma que consistia em seguir o passo a passo por ele descrito utilizando o Software Geogebra. Detalhes sobre essa e outras questões relacionadas foram apresentadas e discutidas em outro trabalho[Rizzi et al. 2011].

Passados 52 meses da oferta do curso, os autores deste trabalho localizaram novamente a página desse professor, cuja tela inicial é mostrada na Figura 1. Decidiu-se pela realização de uma pesquisa semi-estruturada, com uma abordagem qualitativa, de caráter exploratório, objetivando melhor compreender, a partir do entendimento daquele professor, dois aspectos em particular, que são a efetividade de cursos de capacitação no uso de TICs e a utilização das TICs em sala de aula. Da entrevista concedida, os principais aspectos identificados relativos a essas questões são apresentados a seguir.

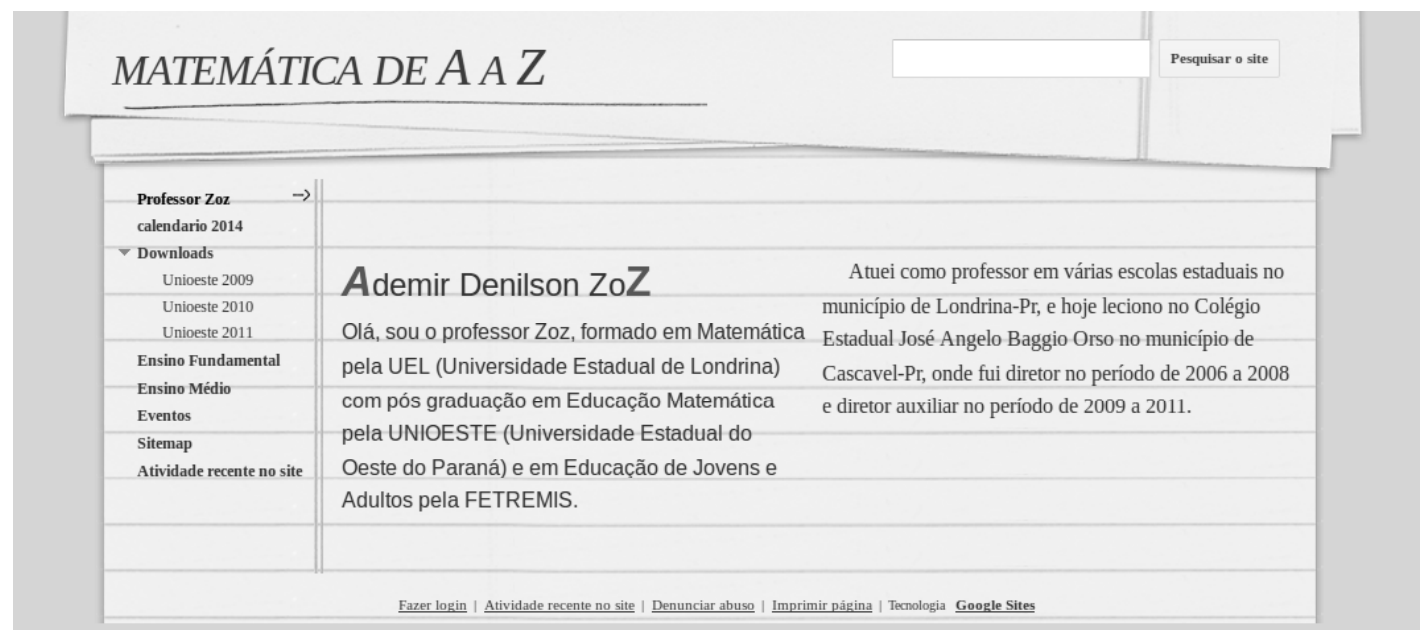

Figura 1. Página inicial do site do professor em junho/2014.

Com relação à efetividade de cursos de capacitação no uso de TICs, esse professor concorda que no Estado do Paraná há esforços no sentido de estruturar e manter as escolas objetivando o uso das TICs. Reconhece que existem softwares, a exemplo do Geogebra que podem ser relevantes no processo de ensino e aprendizagem. No entanto, entende que professores têm dificuldades diversas para por em prática o uso das TICs em especial porque os cursos ofertados geralmente são pontuais e requerem que o professor tenha tempo para planejar, construir e usufruir os benefícios dessa utilização. Não dispondo de tempo suficiente, o professor acaba optando por utilizar outros recursos de apoio, geralmente mais disponíveis na instituição de ensino que atua e já utilizados, a exemplo do material concreto e de dobraduras que embora não sejam TICs, são importantes no processo de aprendizagem. Ao ser questionado sobre qual seria o principal motivo que levaria professores que participam de cursos de capacitação a não utilizarem os conhecimentos adquiridos nos cursos de TICs em sala de aula, respondeu que entende que diversos professores participam de cursos de capacitação exclusivamente visando a promoção profissional. 
Com relação à utilização das TICs em sala de aula, concorda que elas podem contribuir efetivamente no processo de ensino e aprendizagem da Matemática. Mas nos últimos anos tem se sentido desmotivado pelo momento difícil que vive a escola pública. Relatou que cada vez mais os alunos estão desinteressados em sua própria formação e os pais estão impotentes ou indiferentes a esta situação. Relatou que não tem mais disponibilizado materiais de apoio, vídeos e exercícios extras no seu web site porque os alunos não a visitam mais. Embora tenham acesso a computadores conectados à internet, alguns tenham notebooks ou outros dispositivos móveis, não há interesse em Matemática ou mesmo em outras matérias. Há interesse sim, no uso das TICs, mas com outras finalidades, não a de aprendizado.

\section{Considerações finais}

Neste trabalho apresentou-se uma síntese sobre análises decorrentes da realização e do acompanhamento de um curso ofertado para professores de Matemática, para construção de web sites. Constatou-se, dentre outros aspectos, que há esforços governamentais no sentido de equipar as escolas e também em preparar o professor através de formação continuada para utilizar as TICs no trabalho escolar. No entanto, participar de cursos de treinamento e capacitação não garante que os temas discutidos nesses cursos contribuam para mudanças, melhorias ou efetividade do trabalho desenvolvido com os alunos.

Se por um lado o tímido uso das TICs pode levar a considerar sobre o desinteresse ou acomodação por parte do professor, há também que se considerar a necessidade de repensar sobre o formato dos cursos ofertados, mas em especial, a realidade atual dos alunos. Nela estão inseridas (ou se constitui desejo de consumo) produtos como celulares, tablets, notebooks, que viabilizam conexões incluindo com as redes sociais como Facebook. Esses produtos e TICs impactam de maneira significativa na Educação Escolar, mais acostumada a desestimular seu uso por parte dos alunos, que neles se concentram em detrimento às atividades escolares. A questão que se coloca é como aproveitar a facilidade de uso, motivação, interesse e possibilidades ofertadas por esses produtos e TICs também para fins educacionais. Com relação aos cursos, é preciso que sejam mais práticos e que tenham continuidade ou acompanhamento e que haja mais estímulo à aproximação dos professores em exercício com a IES que ofertam cursos de licenciatura.

\section{Referências}

Google Sites (2014). https://sites.google.com/.

Rizzi, C. B., Vicente, A., Brun, A. L., Cruz, J. Z. S., and Rizzi, R. L. (2011). Páginas Web para Professores de Matemática: Realização de Curso e Acompanhamento de Resultados. In Encontro Nacional de Informática na Educação, ENINED. UNIOESTE.

Youtube (2014). http: / /www - youtube.com/. 